\title{
Estimation of spatial and temporal overlap in three ungulate species in a Mediterranean environment
}

\author{
Michele Zanni $^{1} \cdot$ Francesca Brivio $^{1}$ (1) $\cdot$ Stefano Grignolio ${ }^{1} \cdot$ Marco Apollonio $^{1}$
}

Received: 10 June 2020 / Accepted: 20 November 2020 / Published online: 2 December 2020

(C) The Author(s) 2020

\begin{abstract}
Interspecific interactions are key drivers in structuring animal communities. Sympatric animals may show such behavioural patterns as the differential use of space and/or time to avoid competitive encounters. We took advantage of the ecological conditions of our study area, inhabited by different ungulate species, to investigate the spatial and temporal distribution of Capreolus capreolus, Dama dama and Sus scrofa. We estimated intraspecific interaction arising from the concomitant use of resources by using camera trapping. We collected 2741 videos with the three ungulates, which showed peculiar activity patterns. The three species were observed in all the habitat types of the study area over the four seasons, thus highlighting an evident spatial overlap. Moreover, our analysis demonstrated that the three species did not avoid each other through temporal segregation of their activities, rather showing a high overlap of daily activity rhythms, though with differences among the species and the seasons. Despite the high spatial and temporal overlap, the three species seemed to adopt segregation through fine-scale spatial avoidance: at an hourly level, the proportion of sites where the species were observed together was relatively low. This spatiotemporal segregation revealed complex and alternative behavioural strategies, which likely facilitated intra-guild sympatry among the studied species. Both temporal and spatio-temporal overlap reached the highest values in summer, when environmental conditions were more demanding. Given these results, we may presume that different drivers (e.g. temperature, human disturbance), which are likely stronger than interspecific interactions, affected activity rhythms and fine-scale spatial use of the studied species.
\end{abstract}

Keywords Activity rhythms $\cdot$ Fallow deer $\cdot$ Interspecific interaction $\cdot$ Roe deer $\cdot$ Spatio-temporal overlap $\cdot$ Wild boar

\section{Introduction}

Interspecific interactions are key drivers in structuring animal communities (e.g. Gause 1934; Hutchinson 1959) and may affect distribution, resource use, behaviour and population dynamics of interacting species (Sinclair and NortonGriffiths 1982; Putman and Putman 1996; Forsyth and Hickling 1998; Latham 1999; Murray and Illius 2000). Among animal species, at least four types of interactions were described (Krebs 1985): two positive (mutualism and commensalism) and two negative (predation and competition)

Communicated by: Teresa Abaigar Ancín

Francesca Brivio

fbrivio@uniss.it

1 Department of Veterinary Medicine, University of Sassari, Via Vienna 2, 07100 Sassari, Italy ones. Interspecific competition occurs when species of the same trophic level share the same resources with limited availability (De Boer and Prins 1990), which may result in a species negatively affecting the fitness of the other. Competition was described across several taxa (insecta: Human and Gordon 1996; reptiles: Polo-Cavia et al. 2009; fish: Bergstrom and Mensinger 2009; birds: Maron et al. 2011), and it is the most frequent interspecific interaction in ungulates (Latham 1999). Researchers described two main patterns of competition in ungulates: resource and interference competition. The former refers to direct interactions between two or more species which use and compete for shared resources (food and space, Latham 1999). The latter includes adverse social interactions as well as the negative impact of a species on the environment, thus reducing its quality for other species (Latham 1999).

Competitive interactions may occur at both spatial and temporal levels. However, spatial and temporal interactions are not always estimated properly and simultaneously 
(Lewis et al. 2015; Swanson et al. 2016; Karanth et al. 2017; Cusack et al. 2017). Sympatric animals may show such behavioural patterns as the differential use of space and/or time to avoid competitive encounters (Karanth and Sunquist 1995; Durant 1998). Subordinate competitors may avoid locations in which activity levels and/or population density of dominant species are high (Sherry 1979). Likewise, species may adapt their circadian activity patterns to reduce temporal activity overlaps (Carothers et al. 1984).

Wild animals showed a vast array of daily and seasonal activity patterns, which are the result of a complex compromise between best time for feeding, social activity and environmental constraints (Aschoff 1963). Theoretically, time budgeting is usually considered a process of optimisation. The time spent for an activity may increase until costs do not exceed benefits (MacArthur and Pianka 1966). Consequently, we may expect changes in activity patterns as the quality and quantity of environment resources change. Moreover, activity rhythms are likely influenced by predation risk as well as by interspecific competition. For these reasons, the study of spatial and temporal distribution of activity in sympatric species may contribute to understand interspecific competition.

Camera traps are cost-effective, non-invasive and highly efficient tools to collect data and are increasingly used to determine the potential relationship among sympatric species (Di Bitetti et al. 2009; Foster et al. 2013; Tambling et al. 2015; Cusack et al. 2017; Mori et al. 2020). Camera trapping has been widely used in ecology and conservation to investigate the distribution of species, estimate population density and assess biodiversity (O'Connell et al. 2011; Burton et al. 2015; Steenweg et al. 2017). This methodology was also applied to the study of activity rhythms with encouraging results (Tobler et al. 2008; Centore et al. 2018; Caruso et al. 2018; Lashley et al. 2018). More specifically, camera trapping offers the possibility to consider the activity patterns and space use of different species at the same time in the same recording area (Monterroso et al. 2014; Centore et al. 2018; Caruso et al. 2018; Mori et al. 2020) to estimate intraspecific competition arising from the concomitant use of resources.

We investigate the spatial and temporal distribution of activity of roe deer Capreolus capreolus, fallow deer Dama dama and wild boar Sus scrofa. We took advantage of the ecological conditions of our study area, a large fenced area inhabited by these species, and ascertained whether they adopted behavioural strategies to avoid potential competitive encounters among each other. Given the similar feeding habits of the two deer species, their different size and social habits and the competition that may arise between them (Ferretti et al. 2011), we predicted (1) a limited overlap of their activity rhythms. Moreover, given the wild boar's predatory habit on deer fawns, we also predicted that (2) the activities of these species seldom overlapped during deer fawning period, i.e. from late April to the end of June.

\section{Materials and methods}

\section{Study area}

The Presidential Estate of Castelporziano is a protected area located at about $20 \mathrm{~km}$ south-west of Rome. It represents one of the most important Mediterranean forests still existing in Italy.

The area is part of the Mediterranean climatic region, in particular, the mesothermal Mediterranean region (Blasi 1996), characterised by hot and dry summers and cold and rainy winters. During the year of data collection, monthly mean temperature ranged from $6.4{ }^{\circ} \mathrm{C}$ in January to $26.6{ }^{\circ} \mathrm{C}$ in August (Fig. S1 in Online Resource). The estate represents a biologically interesting environmental system thanks to the presence of a wide variety of natural environments, such as newly formed and old dunes, wetlands, Mediterranean scrubland, evergreen (Quercus ilex, Quercus suber, Pinus pinea, Eucalyptus spp) and deciduous forests (Quercus robur, Quercus frainetto, Quercus cerris, Carpinus orientalis) Grignetti et al. 1997; Pignatti et al. 2001).

The estate is a 6000-ha wide, fenced, rather flat area. In the past, it was mainly used for farming, forestry, livestock breeding and hunting activities. Nowadays, about 600 ha are devoted to cereal crops and livestock breeding (horses and cows). Wild ungulates in this area are wild boar, fallow deer, roe deer and red deer (Cervus elaphus), with an estimated population size of 2600 wild boars, 695 fallow deer, 150 roe deer and 128 red deer (ISPRA 2017). Wild boar and fallow deer are culled each year (mean \pm standard deviation, $410.67 \pm 251.44$ and $218.67 \pm 86.29$ heads during last 3 years, respectively) during autumn/winter in order to keep their number stable.

\section{Data collection}

We monitored the ungulate species by using camera trapping during four 30-day sessions, one for each season: autumn (from 12 November to 16 December 2016), winter (from 11 February to 12 March 2017), spring (from 8 May to 6 June 2017) and summer (from 31 July to 28 August 2017).

In order to select camera stations, we overlaid a $1 \times 1 \mathrm{~km}$ grid onto the study area. From this grid, we randomly selected 40 cells and put the camera waypoint in their centroids. The randomisation of the 40 stations was stratified on the area size of each habitat, meaning that the proportion of stations inside each habitat mirrored the proportion of that habitat inside the study area (Table S1 in Online Resource). Camera waypoints were digitised in Quantum GIS (3.4.4) and located 
in the field by means of a handheld GPS. Within each camera waypoint, we searched for the spot with the best light condition in close proximity and placed the camera station. On average, we placed camera stations $946.32 \pm 196.63 \mathrm{~m}$ apart. During each season, the survey was conducted by using 20 camera traps (UOVision UV595-HD and IR PLUS BF $110^{\circ}$ ), which were placed for 2 weeks in 20 stations randomly selected out of the 40 available ones and then relocated in the other 20 stations for 2 more weeks.

Camera traps were secured to trees and wooden poles at an average height of 60-70 $\mathrm{cm}$ from the ground and adequately hidden from the animals' sight. To prevent too many animals being attracted and avoid any modification of their behaviour, no lure or bait was used at the camera stations. The position of camera traps and the range of vision were the same during the four sampling seasons. At all camera stations, we set the cameras to operate $24 / 7$. Cameras were triggered by motion and programmed to take a 30 -second video, with a 5 -second delay between consecutive triggers. We checked camera stations at least weekly to replace camera batteries and memory card when needed.

We extracted the habitat type surrounding each camera station from a 10-m resolution digital map of vegetation (Grignetti et al. 1997). We pooled the habitats recognised by Grignetti et al. (1997) in 5 main classes: deciduous oak forest, evergreen oak forest, pine forest, mixed forest and grassland (Fig. 1).

All applicable international, national and institutional guidelines for animal care and use were strictly followed.

\section{Data analysis}

For each camera trap record, we identified ungulate species, date, time and habitat type. We defined distinguished records of the same species at the same camera station as independent when pictures were taken at least 30 min apart (Linkie and Ridout 2011b), thus reducing pseudoreplication biases (Meredith and Ridout 2014). Only independent records were used in the subsequent analyses. We estimated activity levels of ungulate species for which we had a reasonable number of records, defined by inspecting the distribution of sample sizes. Red deer were detected only 39 times, while roe deer, fallow deer and wild boar were recorded 267, 737 and 1737 times, respectively. As a limited sample size may negatively affect the accuracy and precision of activity curve estimates (Lashley et al. 2018), we excluded red deer from the analyses.

\section{Spatial overlap analysis}

For each camera station and species, we calculated capture frequency as the number of independent sightings per camera-day, by dividing the total number of recorded individuals of that species by the number of days in which the camera trap was active. To prevent biased analyses owing to the different population sizes of each species, detection probability for each season was obtained by dividing the number of daily detections (capture frequency) at each station by the total number of detections for the corresponding species (wild boar, fallow deer and roe deer):

$D P=\left(\frac{C F_{\text {station } i}}{\sum_{\text {station } 1-i} C F}\right)$

in which $D P$ stands for detection probability and $\mathrm{CF}$ for capture frequency.

In order to verify whether the three ungulates showed a differential use of space over the four seasons, we modelled $D P$ by using generalised linear mixed models (GLMMs) with a Gaussian distribution of errors by using the nlme package in $\mathrm{R}$ (Pinheiro et al. 2018). DP was arcsin-root-transformed in order to improve normality of residuals and to reduce skewness. Species, season, habitat type and their interactions were included in the model as fixed factors. Camera station ID was fitted as a random intercept to control for the influence of camera-related factors (e.g. vegetation cover, distance to water). Based on the model predictions, we derived the estimated marginal means (EMMs) for each factor and interaction included in the model. We tested pairwise comparisons of EMMs by using the emmeans package in R (Lenth 2020).

\section{Temporal overlap analysis}

To carry out the temporal overlap analysis, each individual captured by a camera trap record was treated as a single observation in the dataset. The temporal distribution of observations of each species was used to represent its daily activity budgets. Firstly, we converted the time of each capture event into radians to account for the circular distribution of the time of day (Meredith and Ridout 2014; Rowcliffe et al. 2014). For each species, we estimated seasonal activity patterns by fitting a circular kernel density distribution to radian time-of-day data by means of the fitact function in the activity package in $\mathrm{R}$ (Rowcliffe 2016), which provided the percentage of activity time (activity level) during the day ( $24 \mathrm{~h})$. Then, we calculated the percentage of activity time during daylight hours by means of the densityPlot function, by taking into consideration sunrise and sunset times for the study area (obtained from the website https://www.usno.navy.mil/). We calculated the percentage of activity time during nocturnal hours by subtracting the percentage of daylight activity from the total (24 h). Furthermore, we used the compareAct function, which uses a Wald test, to compare the activity levels of each species during the different seasons.

To determine the activity overlaps among the three species, we calculated the coefficients of overlapping $(\Delta)$ in a pairwise 


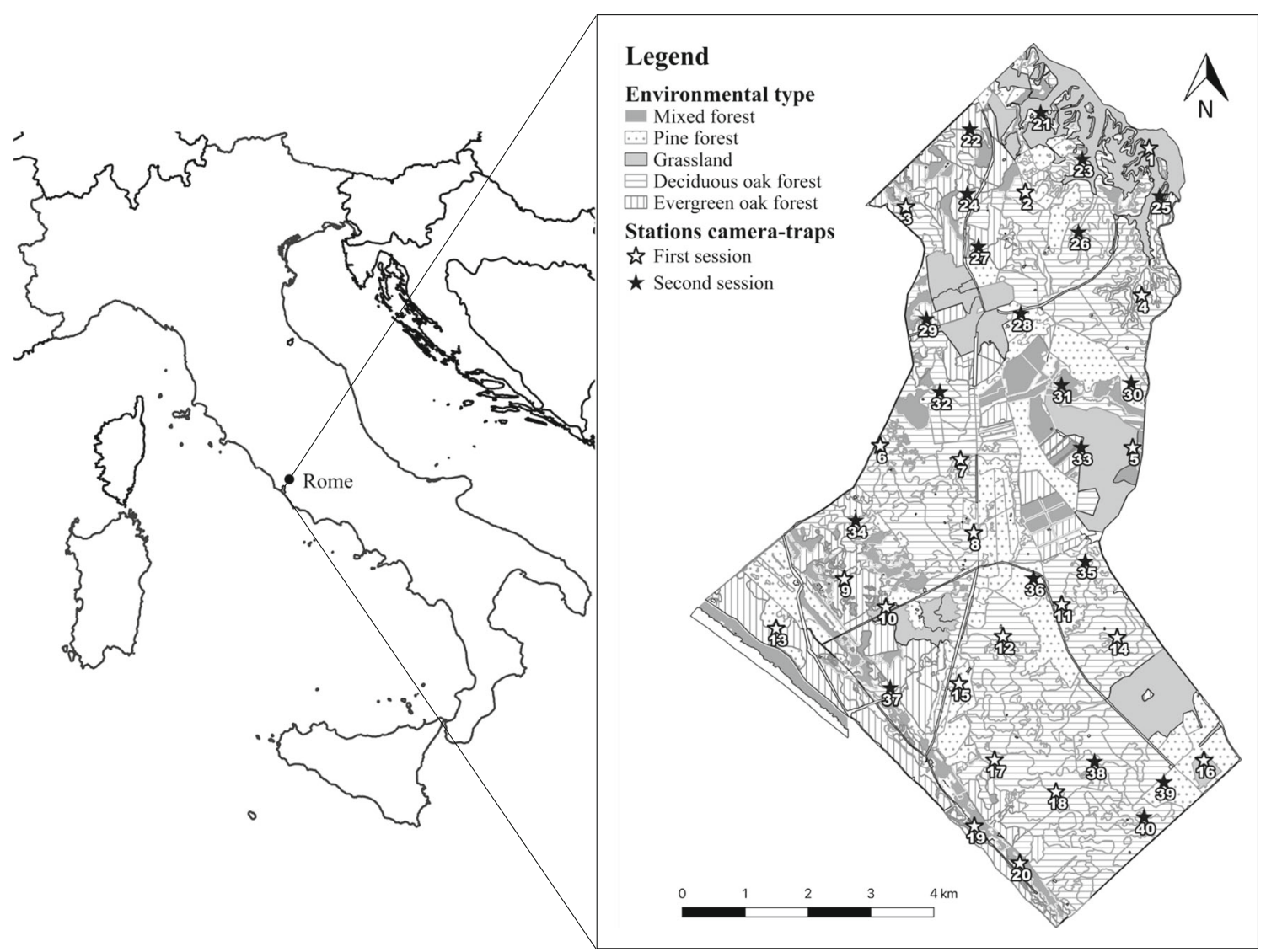

Fig. 1 Map of Italy (left) showing the localisation of in the Estate of Castelporziano (Rome, Italy) and an enlargement of the map (right) with the distribution of camera traps inside the study area.

We used Quantum GIS (3.4.4) Medeira graphics program to create this figure.

manner for each season by using the overlap package in $\mathrm{R}$ (Ridout and Linkie 2009). The $\Delta$ coefficient measures the extension of the overlap between two kernel density estimates by taking the minimum density function from two sets of samples compared at each point in time. The area under both density curves was considered an overlap. The coefficient of overlapping ranged from 0 (no overlap) to 1 (complete overlap; Ridout and Linkie 2009; Linkie and Ridout 2011a). We used $\Delta_{4}$ estimator, which was recommended for large sample sizes ( $>75$ camera records Meredith and Ridout 2014). We calculated the $95 \%$ confidence intervals of each overlap index by using smoothed bootstrap with 1,000 resamples (Meredith and Ridout 2014).

\section{Spatio-temporal overlap analysis}

We evaluated the spatio-temporal overlap following the methodology proposed by Karanth et al. (2017). For each season and species, we created a matrix in which we verified the hourly presence of the species at all camera stations: the rows of the matrix represented the camera stations and the columns the hourly intervals of the diel cycle. Each cell of the matrix contained the total number of detections of the species at a particular site during a specific hourly interval, aggregated throughout the entire season. We then calculated the proportion of camera stations, at each hourly interval, when (i) each species was detected alone, in the absence of the other species, (ii) detection of activity of any two species overlapped and (iii) all three species were active. The proportions were calculated for each hourly interval by dividing the number of camera stations where the species were recorded (alone, in pairs, all together) by the total number of stations where the species were actually detected. Finally, for each species and season, we calculated the hourly average and its relative standard error.

\section{Results}

During the four sampling sessions, we recorded 2741 videos: 1737 videos with wild boars, 737 with fallow deer and 267 with roe deer. Throughout the year, all the species were recorded in the five types of environment considered (Table S2 in Online Resource). 
Table 1 Effect of predictor variables (habitat type, species, season and their interactions) on the detection probability of wild boar, fallow deer and roe deer over the four seasons of data collection in the Estate of Castelporziano (Rome, Italy)

\begin{tabular}{lcccc}
\hline & numDF & denDF & $F$ value & $P$ value \\
\hline Intercept) & 1 & 385 & 270.59 & $<0.001$ \\
Habitat type & 4 & 35 & 0.59 & 0.672 \\
Species & 2 & 385 & 4.18 & 0.016 \\
Season & 3 & 385 & 0.34 & 0.793 \\
Habitat*Species & 8 & 385 & 5.50 & $<0.001$ \\
Habitat*Season & 12 & 385 & 1.85 & 0.038 \\
Species*Season & 6 & 385 & 0.42 & 0.868 \\
Habitat*Species*Season & 24 & 385 & 0.86 & 0.658 \\
\hline
\end{tabular}

The results of the GLMM (Table 1) showed that DP significantly varied according to the species, with a higher probability to detect wild boar. However, the pairwise comparison of EMMs showed that this difference was not statistically significant (Table S3 in Online Resource). The two-way interaction between species and habitat type showed that throughout the monitoring period, the patterns of $D P$ were significantly different among the species. Specifically, wild boar was detected more frequently in grassland $(D P=0.22 \pm 0.02$, mean \pm standard error) with respect to both fallow deer ( $D P$, $0.06 \pm 0.02)$ and roe deer $(D P, 0.07 \pm 0.02)$. Moreover, it was detected more frequently in deciduous oak forest $(D P, 0.14 \pm$ $0.02)$ with respect to roe deer $(D P, 0.10 \pm 0.02$, Table $\mathrm{S} 4$ in Online Resource). However, when comparing $D P$ of the three species in the different habitat types during each season, no significant difference was found (Table S5 in Online
Resource). This result highlighted that, when considering the seasonal patterns, the three species showed a clear seasonal spatial overlap (Fig. S2 in Online Resource).

During summer and autumn, wild boar showed higher activity level with respect to winter and spring (Tables 2 and 3), with an equal distribution during daylight and nocturnal hours (Table 2). During winter, wild boar showed mainly nocturnal activity patterns, while during spring its activity was mainly concentrated during daylight hours. Throughout the year, wild boar reached the maximum peak of activity at dusk, with the exception of summer, when it showed two distinct peaks of activity, at dawn and dusk (Fig. 2).

The activity levels of fallow deer were not significantly different during the four seasons (Tables 2 and 3) and diurnal activity was prevalent during spring only. Surprisingly, during autumn and winter, fallow deer showed mainly nocturnal activity patterns (Table 2). Fallow deer did not show welldefined activity peaks during autumn and winter, while its activity seemed to peak at dawn and dusk during spring and summer (Fig. 2).

Roe deer showed similar activity levels over the four seasons (Tables 2 and 3). No clear distribution of activity patterns was observed either during the day or at night: they were mainly diurnal during spring (Table 2) and almost equal during daylight and nocturnal hours in autumn and winter (Table 2). During summer, roe deer shifted to a mainly nocturnal activity (Table 2). During winter and summer, it showed two clear peaks of activity at dawn and dusk. The peak at dawn was delayed during spring and autumn, while the peak at dusk disappeared in spring (Fig. 3).

In general, the activity overlap among the three species was high in all seasons with a $\Delta_{4}$ never lower than 0.63 (Figs. 2, 3
Table 2 Estimates of the proportion of active time during daylight hours and the percentage of active time during the 24-hour cycle over the four seasons of data collection in the Estate of Castelporziano (Rome, Italy)

\begin{tabular}{lllcccc}
\hline Species & Seasons & $N$ & Prop. diurnal & Activity level & $S E$ & $C I$ \\
\hline \multirow{3}{*}{ Wild boar } & Autumn & 859 & $49 \%$ & 0.48 & \pm 0.03 & $0.42-0.54$ \\
& Winter & 214 & $30 \%$ & 0.34 & \pm 0.03 & $0.28-0.40$ \\
& Spring & 262 & $64 \%$ & 0.36 & \pm 0.04 & $0.30-0.46$ \\
& Summer & 402 & $47 \%$ & 0.50 & \pm 0.04 & $0.42-0.58$ \\
\multirow{5}{*}{ Fallow deer } & Autumn & 184 & $40 \%$ & 0.38 & \pm 0.05 & $0.30-0.47$ \\
& Winter & 93 & $37 \%$ & 0.55 & \pm 0.08 & $0.40-0.71$ \\
& Spring & 199 & $53 \%$ & 0.49 & \pm 0.05 & $0.38-0.59$ \\
& Summer & 261 & $45 \%$ & 0.46 & \pm 0.05 & $0.38-0.57$ \\
\multirow{5}{*}{ Roe deer } & Autumn & 47 & $50 \%$ & 0.52 & \pm 0.08 & $0.33-0.64$ \\
& Winter & 87 & $52 \%$ & 0.36 & \pm 0.05 & $0.25-0.46$ \\
& Spring & 62 & $65 \%$ & 0.48 & \pm 0.07 & $0.33-0.59$ \\
& Summer & 71 & $36 \%$ & 0.35 & \pm 0.07 & $0.23-0.50$ \\
\hline
\end{tabular}

$n=$ number of individual records (prop. diurnal = proportion of active time during daylight hours; activity level = estimated percentage of active time during the 24-hour cycle (see Rowcliffe et al. 2014 and the Methods section for more details); $S E=$ standard error for the estimated activity level; $C I=95 \%$ confidence intervals for the estimated activity level) 
and 4). Overall, the season with the highest coefficients of overlapping was summer (range of mean $\Delta_{4}, 0.82-0.88$ ) showing that the drivers of activity forced all the species to be active simultaneously. During autumn, the general overlap estimates provided a range of $\Delta_{4}$ from 0.76 to 0.84 , whereas in winter $\left(\Delta_{4}, 0.64-0.71\right)$ and spring $\left(\Delta_{4}, 0.63-0.77\right)$ results showed a decrease of overlap.

Considering the paired coefficients of overlapping, the highest activity overlap was found between fallow deer and roe deer (Fig. 4), particularly during summer $\left(\Delta_{4}=0.84, C I=\right.$ $0.75-0.88)$. Conversely, the overlap between wild boar and either roe deer or fallow deer was not homogeneous throughout the year, reaching the minimum values in spring (wild boar-roe deer, $\Delta_{4}=0.63, C I=0.53-0.73$, Fig. 3) and winter (wild boar-fallow deer, $\Delta_{4}=0.64, C I=0.56-0.72$, Fig. 2).

Patterns of combined spatio-temporal overlap showed that the species pair overlap was much lower when compared to the exclusively temporal overlap. Generally, the three species were detected together (same station and hourly interval) in less than $12 \%$ of cases, with the only exception of roe deer, which in summer was observed with the other two species at $27 \%$ of the stations where it was detected (Table 4). By comparing pairs, the species that showed the highest level of overlap were fallow deer-wild boar and roe deer-wild boar, particularly during autumn and summer (Table 4). Roe deer was

Table 3 Results of Wald test used to compare activity levels of each species during four different seasons

\begin{tabular}{|c|c|c|c|c|c|}
\hline Species & Seasons & Difference & $S E$ & $W$ & $P$ \\
\hline \multirow[t]{6}{*}{ Wild boar } & Autumn vs winter & 0.14 & 0.05 & 8.88 & 0.003 \\
\hline & Autumn vs spring & 0.12 & 0.05 & 5.48 & 0.019 \\
\hline & Autumn vs summer & -0.02 & 0.05 & 0.23 & 0.632 \\
\hline & Winter vs spring & -0.02 & 0.05 & 0.14 & 0.711 \\
\hline & Winter vs summer & -0.16 & 0.05 & 9.58 & 0.002 \\
\hline & Spring vs summer & -0.14 & 0.06 & 6.44 & 0.011 \\
\hline \multirow[t]{6}{*}{ Fallow deer } & Autumn vs winter & -0.17 & 0.09 & 3.43 & 0.064 \\
\hline & Autumn vs spring & -0.11 & 0.07 & 2.48 & 0.116 \\
\hline & Autumn vs summer & -0.09 & 0.07 & 1.55 & 0.213 \\
\hline & Winter vs spring & 0.06 & 0.10 & 0.44 & 0.507 \\
\hline & Winter vs summer & 0.09 & 0.10 & 0.80 & 0.371 \\
\hline & Spring vs summer & 0.02 & 0.07 & 0.09 & 0.760 \\
\hline \multirow[t]{6}{*}{ Roe deer } & Autumn vs winter & 0.15 & 0.10 & 2.52 & 0.112 \\
\hline & Autumn vs spring & 0.04 & 0.11 & 0.11 & 0.736 \\
\hline & Autumn vs summer & 0.16 & 0.11 & 2.33 & 0.127 \\
\hline & Winter vs spring & -0.12 & 0.09 & 1.61 & 0.204 \\
\hline & Winter vs summer & 0.01 & 0.09 & 0.01 & 0.915 \\
\hline & Spring vs summer & 0.13 & 0.10 & 1.51 & 0.219 \\
\hline
\end{tabular}

Difference $=$ differences between activity estimates during the different seasons; $S E=$ Standard errors of the differences; $W=$ Wald statistics; $P=$ $p$ values ( $H_{0}$ is no difference between estimates)
Fig. 2 Seasonal activity overlap between wild boars and fallow deer. The grey lines show dawn and dusk. $\Delta=$ index of overlap, value in brackets for confidence interval. Records are double plotted on a 48-h time scale to help the interpretation.

We used R (3.6.1) software graphics program to create this figure.

generally the species with the highest level of spatio-temporal overlap (Table 4), reaching the highest values in summer when it was detected alone only in $26 \%$ of the stations. On the contrary, spring was the season when its degree of overlap reached the lowest values. Unlike the temporal overlap, the level of spatio-temporal overlap between roe deer and fallow deer was quite low and never higher than $11 \%$ during all seasons. From a seasonal point of view, the season that showed the lowest percentages of overlap was winter, while summer showed the highest levels of spatio-temporal overlap (Table 4).

\section{Discussion}

The three species were observed in all the habitat types of the study area over the four seasons of our data collection, thus highlighting an evident spatial overlap. Our results showed that the three species did not avoid each other by means of temporal segregation of their activities as their daily activity rhythms highly overlapped. Nevertheless, by using a finer scale analysis of the spatio-temporal dimension, we highlighted the three species' ability to reduce interspecific interactions either by being active at the same hours but in different areas or by using the same areas at different times of the day. This spatio-temporal segregation indicated that, under the ecological conditions of our study area, the three species developed the skills to implement complex and alternative behavioural strategies, which likely facilitated intra-guild sympatry.

According to the limiting similarity theory by Macarthur and Levins (1967), competing species should differ at least for one dimension of their ecological niche: space, time or resource exploitation. In our study, we did not find spatial segregation among the three species. In contrast to other studies (e.g. Mori et al. 2020), spatial partitioning did not seem to play a major role in structuring interspecific coexistence in our study system. It is worth noting that the study area is fenced and surrounded by a territory strongly affected by human presence as it is located in the suburbs of the largest city in Italy (i.e. Rome). Consequently, the spatial overlap we found may be the result of the limitations in dispersal opportunity. Given the high spatial overlap, a considerable potential for overlap in resource exploitation might be expected, particularly between roe deer and fallow deer (Ferretti et al. 2011). On the other hand, interference competition with wild boar might be expected primarily on account of its destructive feeding 

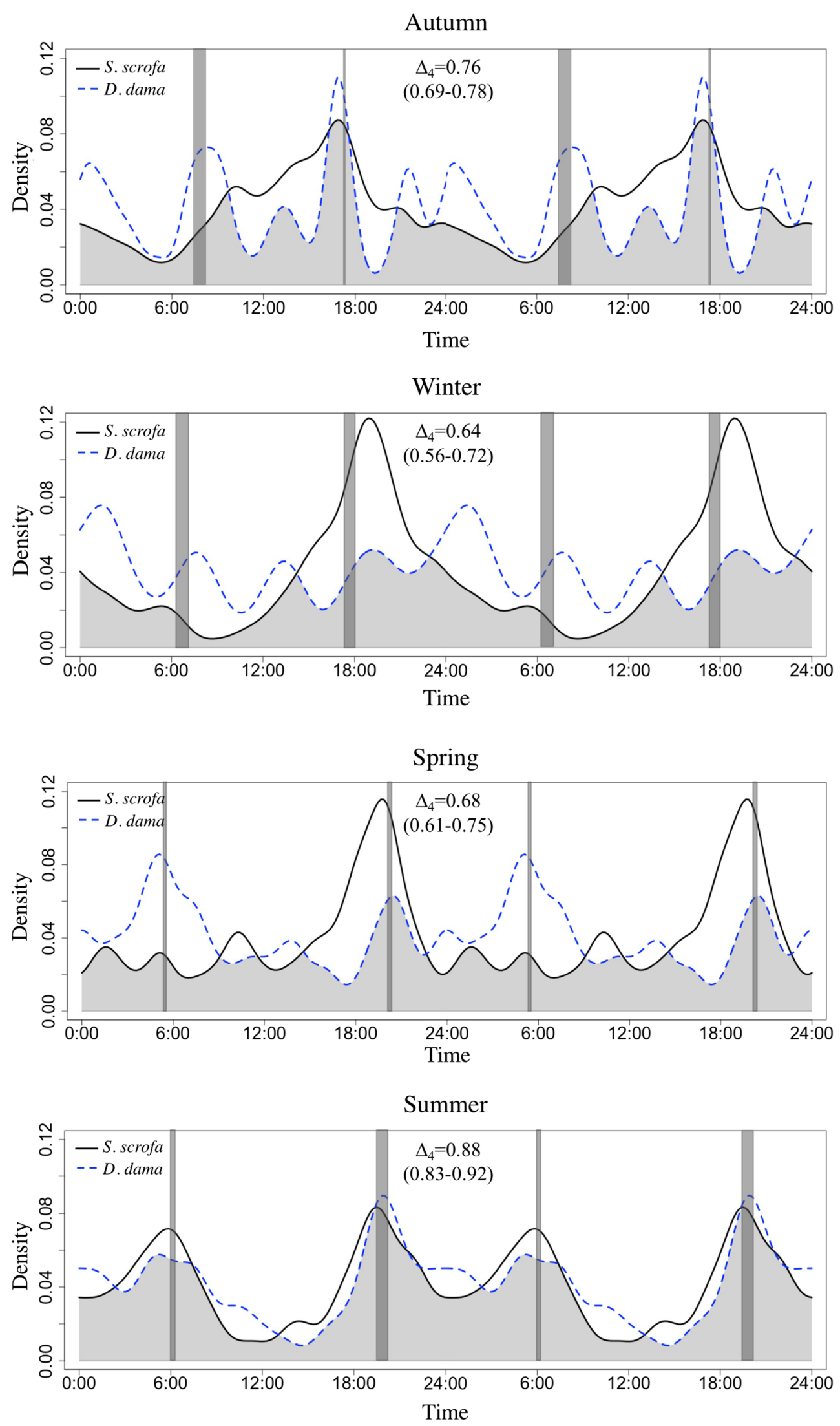
habits (i.e. rooting). Consequently, we expected a differential exploitation of the temporal niche by these sympatric species to avoid resource and interference competition, as shown in other studies (Di Bitetti et al. 2009; Monterroso et al. 2014). For instance, Di Bitetti et al. (2010) showed that the ability of pumas (Puma concolor) and oncillas (Leopardus tigrinus) to adjust their activity patterns to local conditions resulted in a temporal segregation which may facilitate their coexistence and explain the lack of spatial segregation in this assemblage. Contrary to our expectation (1), the three sympatric ungulates apparently did not develop a strategy to avoid being active at the same time. Indeed, our results showed a high temporal overlap among the three species during all seasons. This is consistent with the findings of Mori et al. (2020), which pointed at a high temporal overlap among ungulates species, particularly between wild boar and roe deer. It is interesting to note that, despite the high temporal overlap of activity among the studied species, our results showed that during autumn, winter and spring, roe deer and fallow deer had a peak of activity at dawn, when wild boar was less active. This may be a strategy adopted by the two deer species to avoid being active at dusk, when wild boar reached its peak of activity. Moreover, the three species adopted segregation through fine-scale spatial avoidance as the proportion of sites where the species were observed together was relatively low. In this framework, the species which showed the higher spatio-temporal overlap with other ungulates was roe deer, which was less frequently observed alone, likely on account of its lower density inside the study area. Wild boar, being numerically prevalent, was detected more frequently and this affected the probability of spatiotemporal overlap with fallow and roe deer.

Interestingly, the season when both temporal and spatiotemporal overlap reached the highest values was summer, i.e. the most limiting season in the Mediterranean environment, when food resources were scarce due to drought. On account of these results, we may presume that different drivers, which are likely stronger than interspecific interactions, affected the activity rhythms and fine-scale spatial use. It is now well established that animal activity patterns rely on endogenously fixed rhythms, which are regulated by biological clocks but are also regulated by environmental stimuli, the so-called "zeitgebers" (Aschoff et al. 1982). As a result, activity patterns are strongly affected by different external factors, which may be either environmental (e.g. photoperiod, moon phases, weather conditions, food and water availability) or biotic (e.g. social signals, the presence of predators and human activities; Maloney et al. 2005; Paul et al. 2008). Ambient temperature was repeatedly shown to be one of the most important factors affecting the activity rhythms (Maloney et al. 2005; Pagon et al. 2013; Brivio et al. 2016, 2017; Grignolio et al. 2018) and spatial behaviour of ungulates (Mysterud and Østbye 1999; Marchand et al. 2015; Mason et al. 2014, 2017). By reducing activity when it is warmer and selecting cooler microclimates in their environment (Mysterud and Østbye 1999; Marchand et al. 2015; Brivio et al. 2019), animals may be able to avoid heat stress, while reducing the costs for autonomic thermoregulation (Terrien et al. 2011). Our results are consistent with these findings and suggest that temperature strongly affected the behavioural strategies of the monitored individuals. Indeed, both the temporal and spatio-temporal overlaps were particularly high exactly during the season in which ambient temperature reached the highest levels, i.e. summer (Fig. S1 in Online Resource). On the one hand, the high proportion of nocturnal activity (higher than $50 \%$, Table 2) suggested that high temperatures in summer likely forced the populations involved in this study to be active during the coolest time of the day (i.e. nocturnal hours; Beier and McCullough 1990; Berger et al. 2002; Scheibe et al. 2009; Pita et al. 2011). On the other hand, the high hourly overlap found in the spatio-temporal analysis suggested that the three species in our study area simultaneously used the same habitats. We may suppose that a common driver constrained spatio-temporal choices of the three species: indeed, the high summer temperatures likely pushed the animals towards the coolest parts of the study area.

The activity overlap between wild boar and roe deer, both at temporal and spatio-temporal levels, reached the lowest value in spring, thus confirming our prediction (2). This result was likely affected by the birth of the roe deer fawns and the territorial activity of roe deer males - both occurring in spring. In whitetailed deer (Odocoileus virginianus), females with vulnerable fawns were reported to alter their temporal activity patterns arguably to reduce the risk of encounters with potential predators (Higdon et al. 2019). Wild boar can prey upon small mammals and fawns during their early weeks of life (Loggins et al. 2002; Wilcox and Van Vuren 2009). Consequently, the lower activity and fine-scale spatial overlap in this season might suggest a strategy adopted by roe deer to avoid encounters with wild boar to reduce risks for their fawns.

Our results confirmed the great behavioural plasticity of wild boar (e.g. Cousse et al. 1995; Caley 1997; Russo et al. 1997; Keuling et al. 2008; Barrios-Garcia and Ballari 2012; Podgórski 2013), with considerable variations of its activity rhythms. In our study area, wild boar activity showed a single peak around dusk in autumn, winter and spring, as found in other populations (e.g. Mori et al. 2020). In summer, on the other hand, wild boar showed two distinct peaks at dawn and dusk. Throughout the year, activity patterns switched from predominantly diurnal to predominantly nocturnal to a quite equal distribution between day and night. This is in contrast with the results regarding other Italian populations which were found to be nocturnal throughout the year (Russo et al. 1997; Brivio et al. 2017; Mori et al. 2020). It was suggested that the switch from diurnal to nocturnal activity may be a response to anthropic disturbance in wild boar as well as in other animal species (Keuling et al. 2008; Ohashi et al. 2013; Gaynor et al. 
Fig. 3 Seasonal activity overlap between wild boars and roe deer. The grey lines show dawn and dusk. $\Delta=$ index of overlap, value in brackets for confidence interval. Records are double plotted on a 48-h time scale to help the interpretation.

We used R (3.6.1) software graphics program to create this figure.

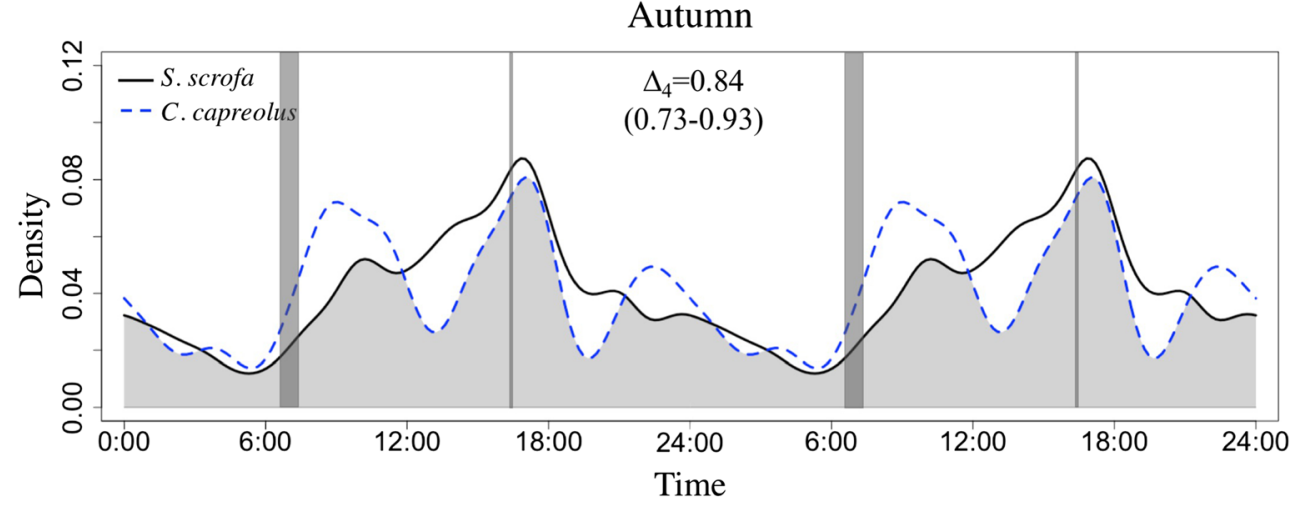

Winter

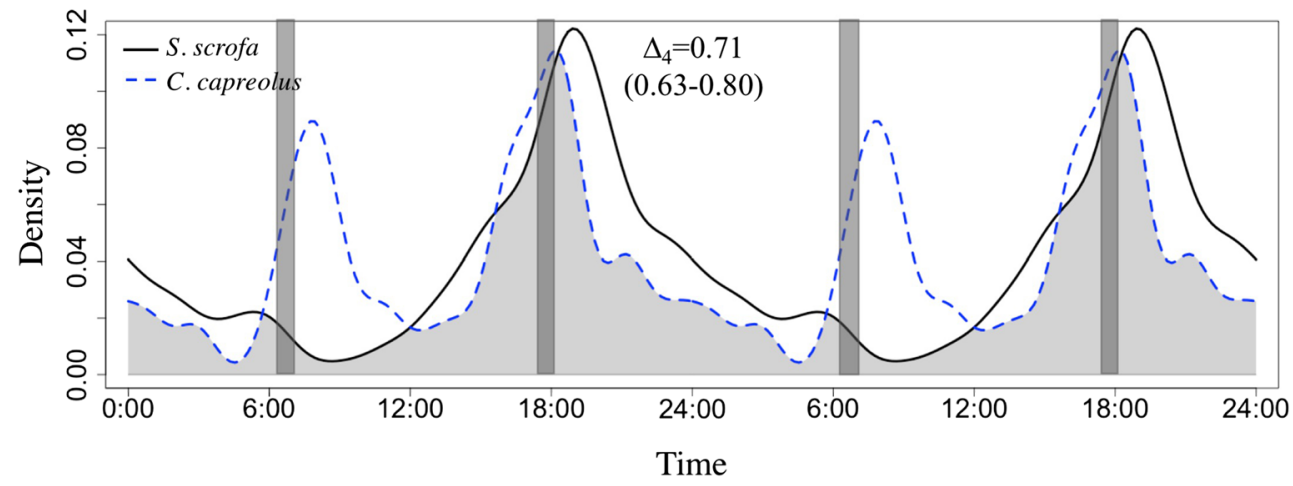

Spring

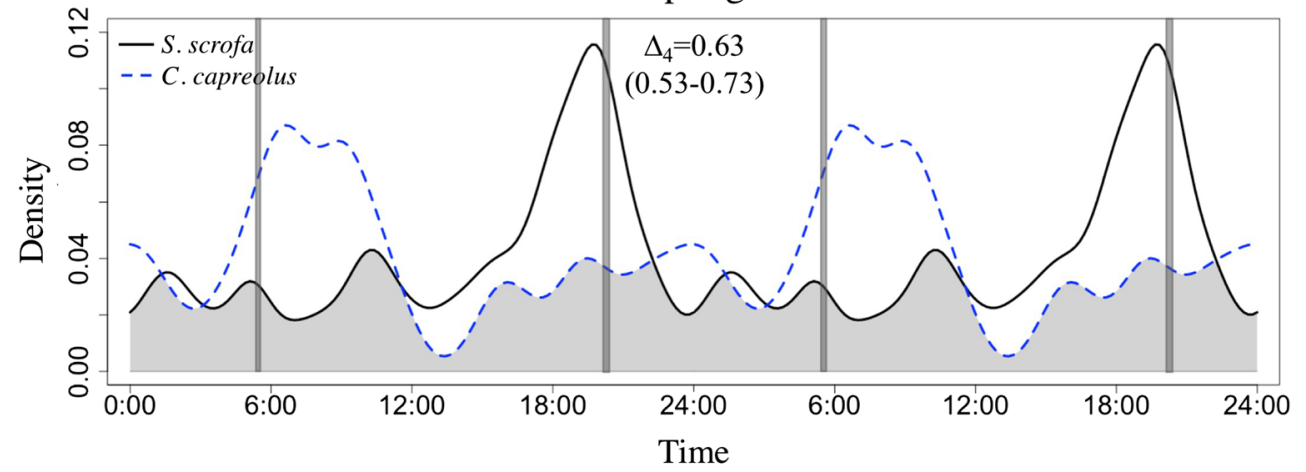

Summer

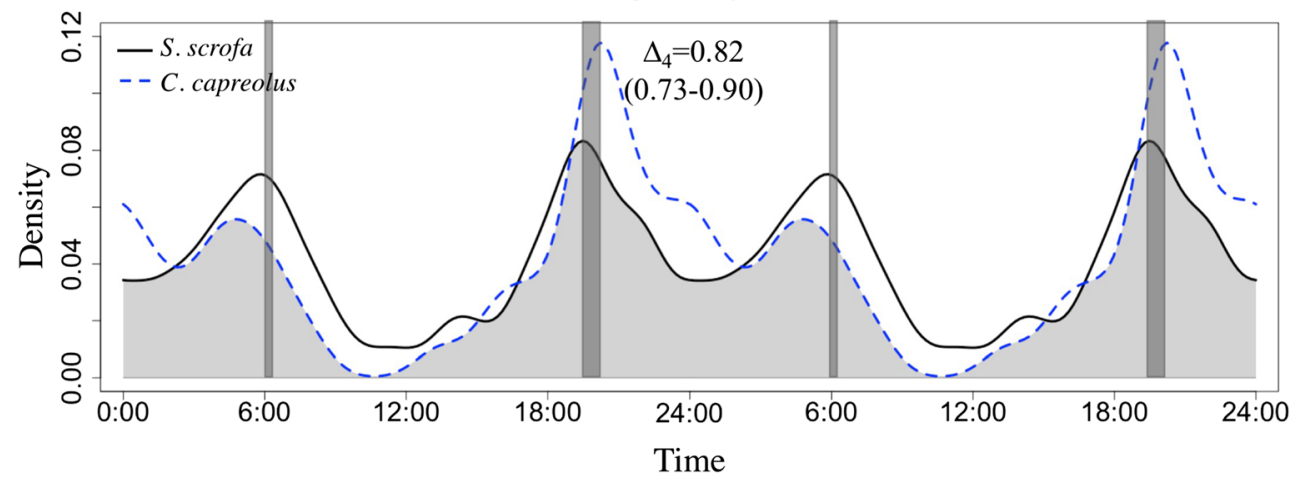


Fig. 4 Seasonal activity overlap between fallow deer and roe deer. The grey lines show dawn and dusk. $\Delta=$ index of overlap, value in brackets for confidence interval. Records are double plotted on a 48-h time scale to help the interpretation.

We used R (3.6.1) software graphics program to create this figure.

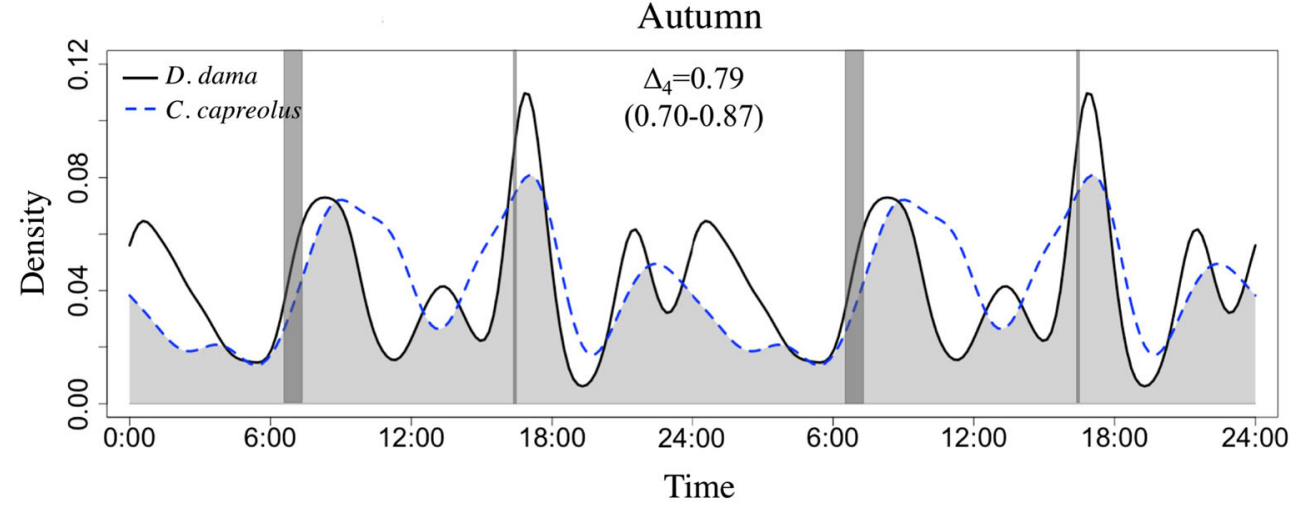

Winter

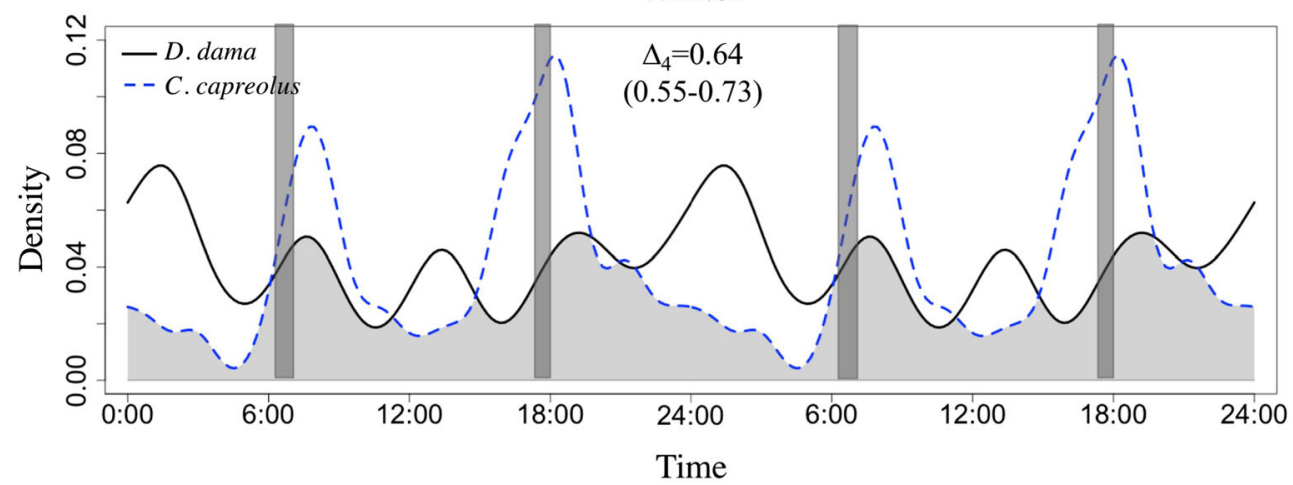

Spring

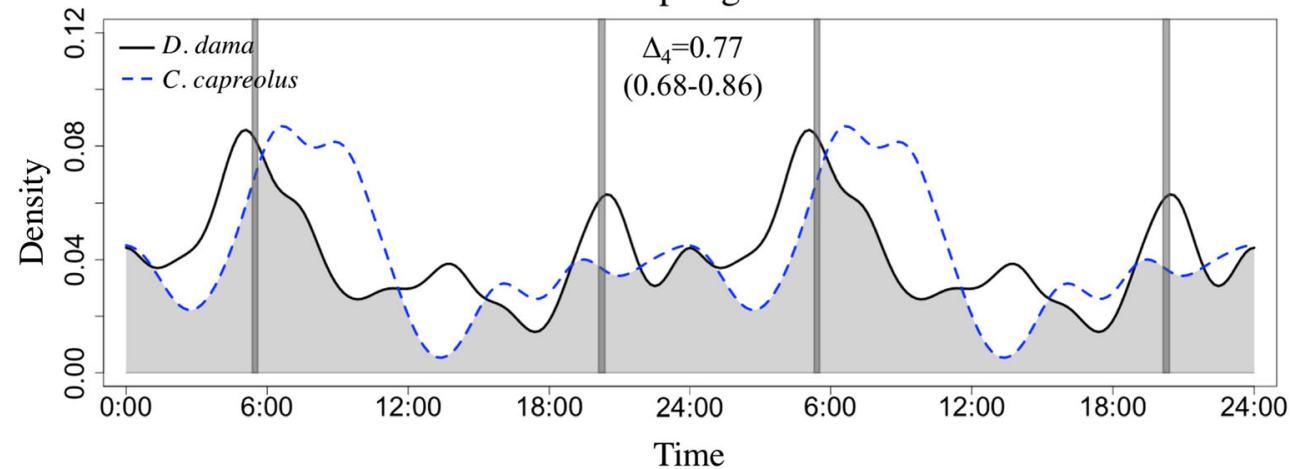

Summer

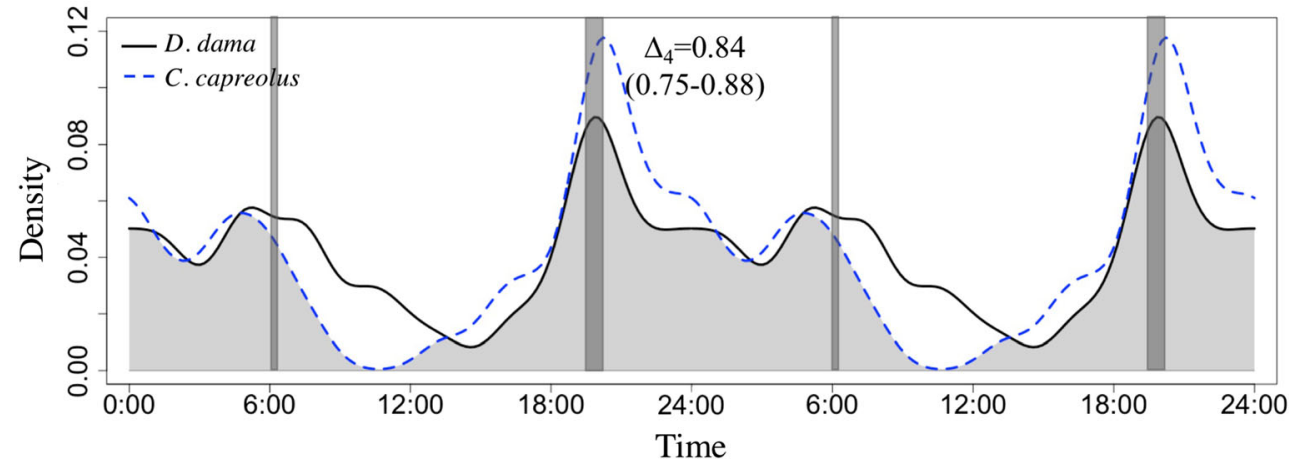


Table 4 Proportion of camera stations, averaged over hourly intervals, when (i) each species was detected alone, in the absence of the other species, (ii) detection of activity of any two species overlapped and (iii) all three species were active

\begin{tabular}{|c|c|c|c|c|}
\hline Type of interaction & Autumn & Winter & Spring & Summer \\
\hline & $0.86(0.09)$ & $0.86(0.14)$ & $0.83(0.15)$ & $0.67(0.23)$ \\
\hline & $0.11(0.01)$ & $0.06(0.02)$ & $0.11(0.02)$ & $0.23(0.04)$ \\
\hline & $0.03(0.01)$ & $0.07(0.02)$ & $0.03(0.01)$ & $0.05(0.02)$ \\
\hline & $0.004(0.003)$ & $0.02(0.01)$ & $0.03(0.02)$ & $0.04(0.01)$ \\
\hline & $0.48(0.06)$ & $0.76(0.04)$ & $0.76(0.05)$ & $0.56(0.05)$ \\
\hline & $0.47(0.06)$ & $0.09(0.03)$ & $0.17(0.05)$ & $0.31(0.04)$ \\
\hline & $0.04(0.02)$ & $0.11(0.03)$ & $0.05(0.02)$ & $0.02(0.02)$ \\
\hline & $0.01(0.01)$ & $0.04(0.03)$ & $0.02(0.01)$ & $0.09(0.04)$ \\
\hline & $0.53(0.07)$ & $0.65(0.07)$ & $0.67(0.07)$ & $0.26(0.05)$ \\
\hline & $0.33(0.08)$ & $0.19(0.06)$ & $0.13(0.04)$ & $0.38(0.08)$ \\
\hline & $0.11(0.04)$ & $0.09(0.03)$ & $0.10(0.04)$ & $0.09(0.03)$ \\
\hline & $0.04(0.03)$ & $0.07(0.05)$ & $0.11(0.05)$ & $0.27(0.06)$ \\
\hline
\end{tabular}

The values in brackets are the relative standard error.

The values in brackets are the relative standard errors

2018). The high nocturnal activity that we found during winter, when culling occurred, supports this theory and is in contrast with the results found by Brivio et al. (2017), which showed that hunting activities did not influence wild boar activity patterns. These differences may be the consequence of the very low levels of human disturbance which characterised our study area throughout the year, with the only exception of the culling period. Consistently, the other culled ungulate, i.e. fallow deer, showed predominantly nocturnal activity during winter in our study area.

Our results on the activity patterns of fallow deer were among the few available data on this species in the Mediterranean environment. According to Caravaggi et al. (2018), whose data referred to Northern Ireland, fallow deer showed prevalently diurnal activity patterns. On the contrary, we found a prevalently nocturnal activity, with the only exception of spring, when it was quite equal during day and night. During winter, the activity pattern was characterised by the presence of several peaks, with a reduced magnitude. However, it is important to stress that we examined the behavioural patterns of a small population for a single year and, therefore, these results have to be taken with caution and further studies are necessary to fully describe the activity patterns of this species. Generally, fallow deer and roe deer are thought to be crepuscular species, showing the highest activity levels at dawn and dusk (Náhlik et al. 2009; Sandor et al.
2011; Krop-Benesch et al. 2013; Pagon et al. 2013; Mori et al. 2020). Several management activities, such as census, rely on this feature. However, our findings did not completely support this statement: only during two seasons (winter and spring for roe deer and fallow deer, respectively), the studied individuals were clearly crepuscular. During summer, they were mostly nocturnal, while during the other seasons fallow deer showed several peaks during diurnal and nocturnal hours, while roe deer seemed to postpone activity after crepuscular hours, particularly in the morning. These results suggest the need to improve knowledge in order to better define management activities.

In conclusion, our study indicated a high degree of spatial and temporal overlap, though a lower overlap was found when data were analysed at a finer scale (i.e. spatio-temporal overlap). This suggests that, even though the species used the same habitats and had similar activity rhythms, they may be able to avoid interspecific interaction by using space during different time periods. On the other hand, by definition, competition can only exist when resources are actually or potentially lacking (Putman and Putman 1996; Tokeshi 2009). The three sympatric ungulates under scrutiny may be able to avoid interspecific competition by using different resources. Diet analysis of each species will likely improve our understanding of the actual interspecific competition among them.

Supplementary Information The online version contains supplementary material available at https://doi.org/10.1007/s13364-020-00548-1.

Acknowledgements We thank the Segretariato della Presidenza della Repubblica for permission to conduct the study at Castelporziano, availability of materials and funding the monitoring program.

We are grateful to ISPRA (Barbara Franzetti) for logistic help and to E. Agnoni, who contributed significantly to data collection. The English version was reviewed and edited by C. Polli.

Author contributions FB and MA originally formulated the idea. MZ and FB conducted fieldwork. MZ, FB and SG performed analyses. FB and $\mathrm{MZ}$ wrote the manuscript and other authors provided editorial advice.

Funding Open access funding provided by Università degli Studi di Sassari within the CRUI-CARE Agreement.

\section{Compliance with ethical standards}

Ethical approval All applicable international, national and institutional guidelines for animal care and use were strictly followed.

Competing interests The authors declare that they have no competing interests.

Open Access This article is licensed under a Creative Commons Attribution 4.0 International License, which permits use, sharing, adaptation, distribution and reproduction in any medium or format, as long as you give appropriate credit to the original author(s) and the source, provide a link to the Creative Commons licence, and indicate if changes were made. The images or other third party material in this article are included in the article's Creative Commons licence, unless indicated otherwise in a 
credit line to the material. If material is not included in the article's Creative Commons licence and your intended use is not permitted by statutory regulation or exceeds the permitted use, you will need to obtain permission directly from the copyright holder. To view a copy of this licence, visit http://creativecommons.org/licenses/by/4.0/.

\section{References}

Aschoff J (1963) Comparative Physiology: Diurnal Rhythms. Annu Rev Physiol 25:581-600. https://doi.org/10.1146/annurev.ph.25. 030163.003053

Aschoff J, Daan S, Honma K-I (1982) Zeitgebers, Entrainment, and Masking: Some Unsettled Questions. In: Aschoff J, Daan S, Groos GA (eds) Vertebrate Circadian Systems. Springer, Berlin Heidelberg, Berlin, Heidelberg, pp 13-24

Barrios-Garcia MN, Ballari SA (2012) Impact of wild boar Sus scrofa in its introduced and native range: a review. Biol Invasions 14:22832300. https://doi.org/10.1007/s10530-012-0229-6

Beier P, McCullough DR (1990) Factors Influencing White-Tailed Deer Activity Patterns and Habitat Use. Wildlife Monographs 3-51

Berger A, Scheibe K-M, Brelurut A, Schober F, Streich WJ (2002) Seasonal Variation of Diurnal and Ultradian Rhythms in Red Deer. Biological Rhythm Research 33:237-253. https://doi.org/10. 1076/brhm.33.3.237.8259

Bergstrom MA, Mensinger AF (2009) Interspecific Resource Competition between the Invasive Round Goby and Three Native Species: Logperch, Slimy Sculpin, and Spoonhead Sculpin. Transactions of the American Fisheries Society 138:1009-1017. https://doi.org/10.1577/T08-095.1

Blasi C (1996) II fitoclima d'Italia. Giornale botanico italiano 130:166176. https://doi.org/10.1080/11263509609439523

Brivio F, Bertolucci C, Tettamanti F, Filli F, Apollonio M, Grignolio S (2016) The weather dictates the rhythms: Alpine chamois activity is well adapted to ecological conditions. Behav Ecol Sociobiol 70: 1291-1304. https://doi.org/10.1007/s00265-016-2137-8

Brivio F, Grignolio S, Brogi R, Benazzi M, Bertolucci C, Apollonio M (2017) An analysis of intrinsic and extrinsic factors affecting the activity of a nocturnal species: The wild boar. Mammalian Biology 84:73-81. https://doi.org/10.1016/j.mambio.2017.01.007

Brivio F, Zurmühl M, Grignolio S, von Hardenberg J, Apollonio M, Ciuti S (2019) Forecasting the response to global warming in a heatsensitive species. Sci Rep 9:3048. https://doi.org/10.1038/s41598019-39450-5

Burton AC, Neilson E, Moreira D, Ladle A, Steenweg R, Fisher JT, Bayne E, Boutin S (2015) REVIEW: Wildlife camera trapping: a review and recommendations for linking surveys to ecological processes. J Appl Ecol 52:675-685. https://doi.org/10.1111/13652664.12432

Caley P (1997) Movements, Activity Patterns and Habitat Use of Feral Pigs (Sus scrofa) in a Tropical Habitat. Wildl Res 24:77. https://doi. org/10.1071/WR94075

Caravaggi A, Gatta M, Vallely M-C, Hogg K, Freeman M, Fadaei E, Dick JTA, Montgomery WI, Reid N, Tosh DG (2018) Seasonal and predator-prey effects on circadian activity of free-ranging mammals revealed by camera traps. PeerJ 6:e5827. https://doi.org/10. 7717/peerj.5827

Carothers JH, Jaksić FM, Jaksic FM (1984) Time as a Niche Difference: The Role of Interference Competition. Oikos 42:403. https://doi.org/ $10.2307 / 3544413$

Caruso N, Valenzuela AEJ, Burdett CL, Luengos Vidal EM, Birochio D, Casanave EB (2018) Summer habitat use and activity patterns of wild boar Sus scrofa in rangelands of central Argentina. PLoS ONE 13:e0206513. https://doi.org/10.1371/journal.pone.0206513
Centore L, Ugarković D, Scaravelli D et al (2018) Locomotor activity pattern of two recently introduced non-native ungulate species in a Mediterranean habitat. Folia Zoologica 67:1-8. https://doi.org/10. 25225/fozo.v67.i1.a1.2018

Cousse S, Janeau G, Spitz F, Cargnelutti B (1995) Temporal ontogeny in the wild boar (Sus scrofa L.): a systemic point of view. Journal of Mountain Ecology 3

Cusack JJ, Dickman AJ, Kalyahe M, Rowcliffe JM, Carbone C, MacDonald DW, Coulson T (2017) Revealing kleptoparasitic and predatory tendencies in an African mammal community using camera traps: a comparison of spatiotemporal approaches. Oikos 126: 812-822. https://doi.org/10.1111/oik.03403

De Boer WF, Prins HHT (1990) Large herbivores that strive mightily but eat and drink as friends. Oecologia 82:264-274. https://doi.org/10. 1007/BF00323544

Di Bitetti MS, Di Blanco YE, Pereira JA et al (2009) Time Partitioning Favors the Coexistence of Sympatric Crab-Eating Foxes (Cerdocyon thous) and Pampas Foxes (Lycalopex gymnocercus). J Mammal 90:479-490. https://doi.org/10.1644/08-MAMM-A-113.1

Di Bitetti MS, De Angelo CD, Di Blanco YE, Paviolo A (2010) Niche partitioning and species coexistence in a Neotropical felid assemblage. Acta Oecologica 36:403-412. https://doi.org/10.1016/j.actao. 2010.04.001

Durant SM (1998) Competition refuges and coexistence: an example from Serengeti carnivores. Journal of Animal Ecology 67:370 386. https://doi.org/10.1046/j.1365-2656.1998.00202.x

Ferretti F, Sforzi A, Lovari S (2011) Behavioural interference between ungulate species: roe are not on velvet with fallow deer. Behav Ecol Sociobiol 65:875-887. https://doi.org/10.1007/s00265-010-1088-8

Forsyth DM, Hickling GJ (1998) Increasing Himalayan tahr and decreasing chamois densities in the eastern Southern Alps, New Zealand: evidence for interspecific competition. Oecologia 113:377-382. https://doi.org/10.1007/s004420050389

Foster VC, Sarmento P, Sollmann R, Tôrres N, Jácomo ATA, Negrões N, Fonseca C, Silveira L (2013) Jaguar and Puma Activity Patterns and Predator-Prey Interactions in Four Brazilian Biomes. Biotropica 45: 373-379. https://doi.org/10.1111/btp.12021

Gause G (1934) The struggle for existence (reprinted 1964). Hafner, New York, USA

Gaynor KM, Hojnowski CE, Carter NH, Brashares JS (2018) The influence of human disturbance on wildlife nocturnality. Science 360: 1232-1235. https://doi.org/10.1126/science.aar7121

Grignetti A, Salvatori R, Casacchia R, Manes F (1997) Mediterranean vegetation analysis by multi-temporal satellite sensor data. Int $\mathrm{J}$ Remote Sensing 18:1307-1318. https://doi.org/10.1080/ 014311697218430

Grignolio S, Brivio F, Apollonio M, Frigato E, Tettamanti F, Filli F, Bertolucci C (2018) Is nocturnal activity compensatory in chamois? A study of activity in a cathemeral ungulate. Mammalian Biology 93:173-181. https://doi.org/10.1016/j.mambio.2018.06.003

Higdon SD, Diggins CA, Cherry MJ, Ford WM (2019) Activity patterns and temporal predator avoidance of white-tailed deer (Odocoileus virginianus) during the fawning season. J Ethol 37:283-290. https:// doi.org/10.1007/s10164-019-00599-1

Human KG, Gordon DM (1996) Exploitation and interference competition between the invasive Argentine ant, Linepithema humile, and native ant species. Oecologia 105:405-412. https://doi.org/10.1007/ BF00328744

Hutchinson GE (1959) Homage to Santa Rosalia or Why Are There So Many Kinds of Animals? The American Naturalist 93:145-159. https://doi.org/10.1086/282070

Karanth KU, Sunquist ME (1995) Prey Selection by Tiger, Leopard and Dhole in Tropical Forests. The Journal of Animal Ecology 64:439. https://doi.org/10.2307/5647

Karanth KU, Srivathsa A, Vasudev D, Puri M, Parameshwaran R, Kumar NS (2017) Spatio-temporal interactions facilitate large carnivore 
sympatry across a resource gradient. Proc R Soc B 284:20161860. https://doi.org/10.1098/rspb.2016.1860

Keuling O, Stier N, Roth M (2008) How does hunting influence activity and spatial usage in wild boar Sus scrofa L.? Eur J Wildl Res 54: 729-737. https://doi.org/10.1007/s10344-008-0204-9

Krebs CJ (1985) Ecology: The Experimental Analysis of Distribution and Abundance. Third edition. Harper and Row, New York, New York, USA. Ecology 1-14

Krop-Benesch A, Berger A, Hofer H, Heurich M (2013) Long-term measurement of roe deer (Capreolus capreolus) (Mammalia: Cervidae) activity using two-axis accelerometers in GPS-collars. Italian Journal of Zoology 80:69-81. https://doi.org/10.1080/11250003. 2012.725777

Lashley MA, Cove MV, Chitwood MC, Penido G, Gardner B, DePerno CS, Moorman CE (2018) Estimating wildlife activity curves: comparison of methods and sample size. Sci Rep 8:4173. https://doi.org/ 10.1038/s41598-018-22638-6

Latham J (1999) Interspecific interactions of ungulates in European forests: an overview. Forest Ecology and Management 120:13-21. https://doi.org/10.1016/S0378-1127(98)00539-8

Lenth R (2020) emmeans: Estimated Marginal Means, aka Least-Squares Means. R package version 1.5.2-1. https://CRAN.R-project.org/ package $=$ emmeans

Lewis JS, Bailey LL, VandeWoude S, Crooks KR (2015) Interspecific interactions between wild felids vary across scales and levels of urbanization. Ecol Evol 5:5946-5961. https://doi.org/10.1002/ ece3.1812

Linkie M, Ridout MS (2011a) Assessing tiger-prey interactions in Sumatran rainforests: Tiger-prey temporal interactions. Journal of Zoology 284:224-229. https://doi.org/10.1111/j.1469-7998.2011. 00801.x

Linkie M, Ridout MS (2011b) Assessing tiger-prey interactions in Sumatran rainforests. Journal of Zoology 284:224-229

Loggins RE, Wilcox JT, Van Vuren D, Sweitzer RA (2002) Seasonal diets of wild pigs in oak woodlands of the central coast region of California. California Fish and Game 88:28-34

Macarthur R, Levins R (1967) The Limiting Similarity, Convergence, and Divergence of Coexisting Species. The American Naturalist 101:377-385. https://doi.org/10.1086/282505

MacArthur RH, Pianka ER (1966) On optimal use of patchy environment. Amer Natur 100:603-609

Maloney SK, Moss G, Cartmell T, Mitchell D (2005) Alteration in diel activity patterns as a thermoregulatory strategy in black wildebeest (Connochaetes gnou). J Comp Physiol A 191:1055-1064. https:// doi.org/10.1007/s00359-005-0030-4

Marchand P, Garel M, Bourgoin G, Dubray D, Maillard D, Loison A (2015) Sex-specific adjustments in habitat selection contribute to buffer mouflon against summer conditions. Behavioral Ecology 26:472-482. https://doi.org/10.1093/beheco/aru212

Maron M, Main A, Bowen M, Howes A, Kath J, Pillette C, Mcalpine CA (2011) Relative influence of habitat modification and interspecific competition on woodland bird assemblages in eastern Australia. Emu - Austral Ornithology 111:40-51. https://doi.org/10.1071/ MU09108

Mason THE, Stephens PA, Apollonio M, Willis SG (2014) Predicting potential responses to future climate in an alpine ungulate: interspecific interactions exceed climate effects. Glob Change Biol 20: 3872-3882. https://doi.org/10.1111/gcb.12641

Mason THE, Brivio F, Stephens PA, Apollonio M, Grignolio S (2017) The behavioral trade-off between thermoregulation and foraging in a heat-sensitive species. Behavioral Ecology 28:908-918. https://doi. org/10.1093/beheco/arx057

Meredith M, Ridout M (2014) Estimates of coefficient of overlapping for animal activity patterns

Monterroso P, Alves PC, Ferreras P (2014) Plasticity in circadian activity patterns of mesocarnivores in Southwestern Europe: implications for species coexistence. Behav Ecol Sociobiol 68:1403-1417. https://doi.org/10.1007/s00265-014-1748-1

Mori E, Bagnato S, Serroni P, Sangiuliano A, Rotondaro F, Marchianò V, Cascini V, Poerio L, Ferretti F (2020) Spatiotemporal mechanisms of coexistence in an European mammal community in a protected area of southern Italy. J Zool 310:232-245. https://doi.org/10.1111/ jzo. 12743

Murray MG, Illius AW (2000) Vegetation modification and resource competition in grazing ungulates. Oikos 89:501-508. https://doi. org/10.1034/j.1600-0706.2000.890309.x

Mysterud A, Østbye E (1999) Cover as a Habitat Element for Temperate Ungulates: Effects on Habitat Selection and Demography. Wildlife Society Bulletin (1973-2006) 27:385-394

Náhlik A, Sándor G, Tari T, Király G (2009) Space use and activity patterns of red deer in a highly forested and in a patchy forestagricultural habitat. Acta Silvatica \& Lignaria Hungarica 5:109-118

O'Connell AF, Nichols JD, Karanth KU (eds) (2011) Camera traps in animal ecology: methods and analyses / Allan F. O'Connell, James D. Nichols, K. Ullas Karanth, editors. Springer, Tokyo; New York

Ohashi H, Saito M, Horie R, Tsunoda H, Noba H, Ishii H, Kuwabara T, Hiroshige Y, Koike S, Hoshino Y, Toda H, Kaji K (2013) Differences in the activity pattern of the wild boar Sus scrofa related to human disturbance. Eur J Wildl Res 59:167-177. https://doi.org/ 10.1007/s10344-012-0661-z

Pagon N, Grignolio S, Pipia A, Bongi P, Bertolucci C, Apollonio M (2013) Seasonal variation of activity patterns in roe deer in a temperate forested area. Chronobiology International 30:772-785. https://doi.org/10.3109/07420528.2013.765887

Paul MJ, Zucker I, Schwartz WJ (2008) Tracking the seasons: the internal calendars of vertebrates. Phil Trans R Soc B 363:341-361. https:// doi.org/10.1098/rstb.2007.2143

Pignatti S, Bianco P, Tescarollo P, Scarascia Mugnozza G (2001) La vegetazione della tenuta presidenziale di Castelporziano. Accademia Nazionale delle Scienze detta dei XL, Scritti e documenti 26:441-708

Pinheiro J, Bates D, DebRoy S, Sarkar D, R Core Team (2018) nlme: Linear and Nonlinear Mixed Effects Models. R package version 3.1137, https://CRAN.R-project.org/package=nlme

Pita R, Mira A, Beja P (2011) Circadian activity rhythms in relation to season, sex and interspecific interactions in two Mediterranean voles. Animal Behaviour 81:1023-1030. https://doi.org/10.1016/j. anbehav.2011.02.007

Podgórski T (2013) Effect of relatedness on spatial and social structure of the wild boar Sus scrofa population in Białowieża Primeval Forest. Doctoral dissertation

Polo-Cavia N, López P, Martín J (2009) Interspecific differences in chemosensory responses of freshwater turtles: consequences for competition between native and invasive species. Biol Invasions 11:431-440. https://doi.org/10.1007/s10530-008-9260-z

Putman RJ, Putman R (1996) Competition and resource partitioning in temperate ungulate assemblies. Springer Science \& Business Media, London, UK

Ridout MS, Linkie M (2009) Estimating overlap of daily activity patterns from camera trap data. JABES 14:322-337. https://doi.org/10.1198/ jabes.2009.08038

Rowcliffe M (2016) activity: Animal Activity Statistics. R package version 1.1

Rowcliffe JM, Kays R, Kranstauber B, Carbone C, Jansen PA (2014) Quantifying levels of animal activity using camera trap data. Methods Ecol Evol 5:1170-1179. https://doi.org/10.1111/2041210X.12278

Russo L, Massei G, Genov PV (1997) Daily home range and activity of wild boar in a Mediterranean area free from hunting. Ethology Ecology \& Evolution 9:287-294. https://doi.org/10.1080/ 08927014.1997.9522888 
Sandor G, Tari T, Dremmel L, et al (2011) University of West-Hungary, Institute of Wildlife Management and Vertebrate Zoology, sandorgyGemk. nyme. hu Key words: fallow deer, daily activity, GPS telemetry

Scheibe KM, Robinson TL, Scheibe A, Berger A (2009) Variation of the phase of the 24-h activity period in different large herbivore species under European and African conditions. Biological Rhythm Research 40:169-179. https://doi.org/10.1080/ 09291010701875070

Sherry TW (1979) Competitive interactions and adaptive strategies of American Redstarts and Least Flycatchers in a northern hardwoods forest. The Auk 96:265-283

Sinclair ARE, Norton-Griffiths M (1982) Does competition or facilitation regulate migrant ungulate populations in the Serengeti? A test of hypotheses. Oecologia 53:364-369. https://doi.org/10.1007/ BF00389015

Steenweg R, Hebblewhite M, Kays R, Ahumada J, Fisher JT, Burton C, Townsend SE, Carbone C, Rowcliffe JM, Whittington J, Brodie J, Royle JA, Switalski A, Clevenger AP, Heim N, Rich LN (2017) Scaling-up camera traps: monitoring the planet's biodiversity with networks of remote sensors. Front Ecol Environ 15:26-34. https:// doi.org/10.1002/fee.1448
Swanson A, Arnold T, Kosmala M, Forester J, Packer C (2016) In the absence of a "landscape of fear": How lions, hyenas, and cheetahs coexist. Ecol Evol 6:8534-8545. https://doi.org/10.1002/ece3.2569

Tambling CJ, Minnie L, Meyer J, Freeman EW, Santymire RM, Adendorff J, Kerley GIH (2015) Temporal shifts in activity of prey following large predator reintroductions. Behav Ecol Sociobiol 69: 1153-1161. https://doi.org/10.1007/s00265-015-1929-6

Terrien J, Perret M, Aujard F (2011) Behavioral thermoregulation in mammals: a review. Front Biosci 16:1428-1444

Tobler MW, Carrillo-Percastegui SE, Leite Pitman R, Mares R, Powell G (2008) An evaluation of camera traps for inventorying large- and medium-sized terrestrial rainforest mammals. Animal Conservation 11:169-178. https://doi.org/10.1111/j.1469-1795.2008.00169.x

Tokeshi M (2009) Species coexistence: ecological and evolutionary perspectives. John Wiley \& Sons

Wilcox JT, Van Vuren DH (2009) Wild Pigs as Predators in Oak Woodlands of California. Journal of Mammalogy 90:114-118. https://doi.org/10.1644/08-MAMM-A-017.1

Publisher's note Springer Nature remains neutral with regard to jurisdictional claims in published maps and institutional affiliations. 